\title{
DESIGN AND DEVELOPMENT OF A COMPONENT BY REVERSE ENGINEERING
}

\author{
Gayatri D. Barai ${ }^{1}$, Sunil S. Shete ${ }^{2}$, Laukik P. Raut ${ }^{3}$ \\ ${ }^{I}$ Student, M. Tech CAD/CAM, Department of Mechanical Engineering, GHRCE, Nagpur \\ ${ }^{2}$ Student, M. Tech CAD/CAM, Department of Mechanical Engineering, GHRCE, Nagpur \\ ${ }^{3}$ Assistant Professor, Department of Mechanical Engineering, GHRCE, Nagpur
}

\begin{abstract}
In this paper, approach for Reverse Engineering (RE) technique using Coordinate Measuring Machine (CMM) and a design software CREO is presented. A part is physically examined with the help of Coordinate Measuring Machine (CMM) \& Point cloud data of a part is generated through scanning. Point cloud data is then exported to CAD software CREO to generate CAD model of a part. Thus, this report describes the processes of Reverse Engineering, from object digitization to CAD model reconstruction and error analysis. A case study of Reverse Engineering using CMM and CAD tool is presented considering a part i.e. Rotor Driven Shaft of Transmission assembly of JADHAO Rotavator is presented and finally important conclusions are drawn.
\end{abstract}

Keywords- Reverse Engineering, Rotavator, CMM, Metallur Scale

\section{INTRODUCTION}

Reverse Engineering has been defined in many different ways. The aim of reverse engineering is to use a physical part to gather complete knowledge about the part, which enables its replication. This knowledge can be anything from general appearance and physical dimensions to working methodology and material properties. In the manufacturing world 'Reverse Engineering' refers to the process of creating engineering design data from existing parts. It recreates or clones the exiting part by acquiring the CAD (Computer Aided Design) of the existing part.

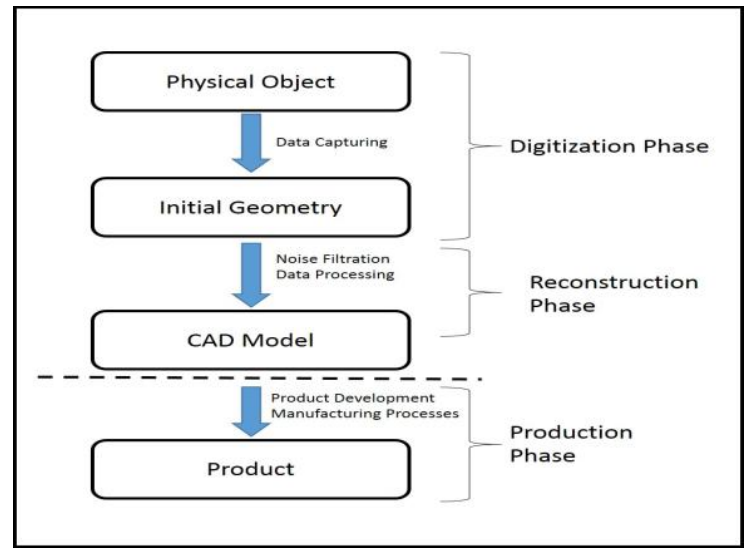

Fig 1 -Computer Aided Reverse Engineering

Need for Reverse Engineering:

- The original manufacturer of a product no longer produces a product.

- There is inadequate documentation of the original design.

- The original manufacturer no longer exists, but a customer needs the product.
- The original design documentation has been lost or never existed.

- To strengthen the good features of a product based on long-term usage of the product.

- To analyse the good and bad features of competitors' product.

- $\quad$ Some bad features of a product need to be designed out. For example, excessive wear might indicate where a product should be improved

- To explore new avenues to improve product performance and features.

- To gain competitive benchmarking methods to understand competitor's products and develop better products.

- The original CAD model is not sufficient to support modifications or current manufacturing methods.

- The original supplier is unable or unwilling to provide additional parts.

- The original equipment manufacturers are either unwilling or unable to supply replacement parts, or demand inflated costs for sole-source parts.

- To update obsolete materials or antiquated manufacturing processes with more current, lessexpensive technologies.

Thus it can be seen that reverse engineering techniques are being used in a wide range of applications and is not restricted to the industrial world. The type of reverse engineering that will be discussed in this thesis is the technique where the physical dimensions of a part are being captured to produce the detailed drawing of the part. In the computer aided manufacturing (CAM) world, this is referred to as Part to CAD conversion, where the geometry of physical objects be captured as digital 3-D CAD Data. 


\subsection{Objectives}

The objectives for the study are as follows:

- $\quad$ To study the Reverse Engineering method \& to utilize the method to find out the critical dimensions.

- To find various critical dimensions of a part by various methods.

- $\quad$ To acquire dimensions using Coordinate Measuring Machine (CMM), CMM scanning \& other methods of scanning accurately.

- To acquire point cloud data of a component through CMM scanning.

- To export cloud point data of CMM (PCDMIS software) to the modeling software (preparation of IGES, STET, STL file) with more accuracy.

- To study modeling software that can be utilized to model the IGES, STEP, STL data to form a CAD model.

- To prepare a CAD model \& obtain the various dimensions of the component.

- To obtain inspection program for error analysis on CMM.

- To suggest a proper method for obtaining the accurate dimensions.

\subsection{Problem Statement}

In this paper work, a component from Jadhao Icons Industry situated in MIDC, Amravati is considered for Reverse Engineering. The CAD model of this component was not available but finished sample was available for Reverse Engineering. Considering the fact that errors in dimension and geometrical features cause failure at the time of assembly and increase rejection rate. Therefore, it was decided to develop this component by Reverse Engineering using CMM and to perform error analysis later on.

\subsection{CMM}

A CMM (Coordinate Measuring Machine) is a device for measuring the physical geometrical characteristics of an object. This machine may be manually controlled by an operator or it may be computer controlled. Measurements are defined by a probe attached to the third moving axis of this machine. Probes may be mechanical, optical, laser, or white light, amongst others. A machine which takes readings in six degrees of freedom and displays these readings in mathematical form is known as a CMM.

\section{LITERATURE REVIEW}

G. C. Gannod et. al (1999) presented a formal approach for reverse engineering. Authors have been suggested many different approaches for reverse engineering in his literature. The availability of such approaches provides the opportunity to study the effect of their combination. In its previous investigations, authors have developed a formal approach for reverse engineering. When applied as a standalone technique, the complexity of this approach is unmanageable. [1]
C. X. (Jack) Feng (2000) have elaborated a computer-aided reverse engineering (CARE) approach. In this approach, a CMM is used to digitize an existing mechanical object, and then a piece of software called ScanPak is used to generate the IGES files of the point data from CMM digitization. Pro/Engineer then is used to create the solid model of the object, and finally the laminated object manufacturing process (LOM - one of the many rapid prototyping technologies) is used to duplicate the object. The methodology is presented, and a case study has been illustrating the approach. Finally, challenges and future research directions in CARE has been identified. [2]

V.H. Chan et.al (2001), finds that two primary aspects of reverse engineering are accomplished by the incorporation of a CCD camera into the CMM system: tool path planning for the touch probe and the identification of separate surfaces on the object. Although use of neural networks for machine vision is quite established, the use segmenting of images with non-constrained boundaries for application in reverse engineering has proved promising. [3]

L Li et al (2002) presented a reverse engineering system for rapid modelling and manufacturing of products with complex surfaces. The system consists of three main components: a 3D optical digitizing system, surface reconstruction software and a rapid prototyping machine. The unique features of the $3 \mathrm{D}$ optical digitizing system include the use of white-light source, and cost-effective and quick image acquisition. The modelling software exports models in STL format, which are used as input to an FDM 2000 machine to manufacture products. The examples are included to illustrate the systems and the methods. [4]

S. Ali (2005) explained that laser scanning presents options that previously used methods do not allow. Damaging parts surfaces due to contact is not a problem with laser scanning. His system uses the IVP 2000 Range Scanner to acquire scanned data and generate a 3D freeform model using Rapid Form 2004. The IVP Range Scanner is equipped with a camera system and laser scanner that acquires the data after scanning. [5]

M. Sokovic et. al (2006) elaborated that how for some product development processes Reverse Engineering (RE) allows to generate surface models by three-dimensional (3D) scanning technique, and consequently this methodology permits to manufacture different parts (for cars, for household appliances) and tools (moulds, dies, press tools) in a short development period. Author shows review of the advantages and weaknesses of different scanning systems. [6]

M. M. Hussain et. al (2008) have studied an object to demonstrate ability of error analysis using coordinate measuring machine. The object reversed in this case study is injection mould with two damaged cavities in the part, without any drawing prints. Using CMM and CAD software point cloud files are created. He further concluded that, if scanning data is converted into datum curves/curves (Blend) scanning itself, $50 \%$ of manual work can be reduced. 
Scanning along and across directions in surface scanning will improve the accuracy of surfaces. Accuracy in surfaces will depend on complexity of shape. The accuracy of surfaces will increase by manipulation of surfaces. [7]

S. Babu et. al (2011), studied about pattern less casting process using CADICAM applications, scanning/digitizing, coordinate measuring arm machine, and 5-axis machine. An adjustable diffuser vane blade used in oil and gas industry was manufactured by reverse engineering and pattern less process starting from a worn out sample. First the blade was digitized by Cimcore-3000i 3D Coordinate Measuring Arm. The obtained point cloud data is imported to Pro/Engineer CADICAM software to develop the 3D model and design the moulds. Then direct sand blocks (cope and drag) milling on Poseidon CNC specific purpose 5-axis machine was adopted completely eliminating any use of patterns. The moulds were directly used for metal pouring at the casting stage. [8]

\section{CONCEPT}

N. Singh (2012) [9] elaborated the concept of Reverse Engineering as the process of duplicating an existing part, subassembly, or product with the aid of drawings, documentation, or a computer model is known as REVERSE ENGINEERING. After a brief introduction, the various stages involved in reverse engineering, and its applications in different fields have been discussed.

\subsection{Stages in Reverse Engineering}

1. Scanning Phase: This phase is involved with the scanning strategy-selecting the correct scanning technique, preparing the part to be scanned, and performing the actual scanning to capture information that describes all geometric features of the part such as steps, slots, pockets, and holes.

2. Point Processing Phase: This phase involves importing the point cloud data, reducing the noise in the data collected, and reducing the number of points. A wide range of commercial software is available for point processing. The output of the point processing phase is a clean, merged, point cloud data set in the most convenient format.

3. Application Geometric Model Development Phase: The generation of cad models from point data is probably the most complex activity within RE because potent surface fitting algorithms are required to generate surfaces that accurately represent the three-dimensional information described within the point cloud data sets.

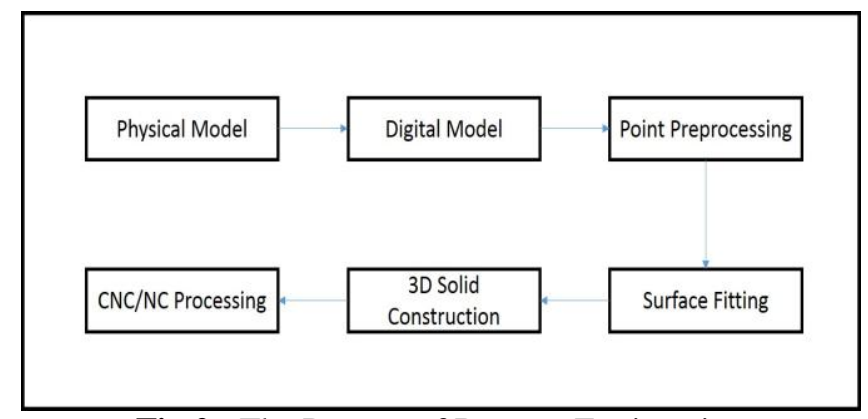

Fig 2 - The Process of Reverse Engineering

\section{MATERIAL \& METHOD}

The component selected for project work is Rotor Driven Shaft of Rotavator. This shaft is used for the transmission of power from Rotor Drive Shaft to the other parts of Rotavator assembly. The Rotor Driven Shaft is shown in the figure 3.

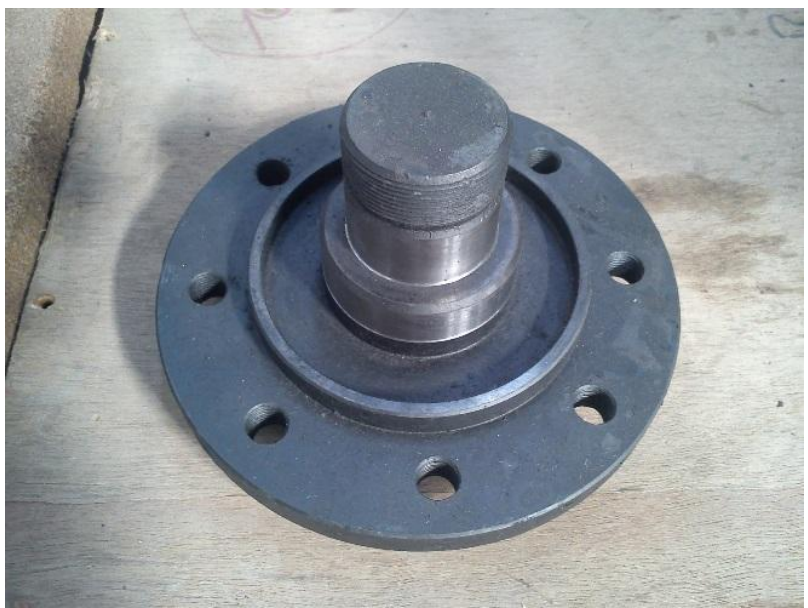

Fig 3 - Rotor Driven Shaft

\subsection{Machine Used}

The Coordinate Measuring Machine used in this study is Brown \& Sharpe Global Classic which is shown in Figure 4. The technical details of this machine are:

\subsection{Design Features}

- Aluminium ultra-rigid frame and patented Tricision and Slant Bridge design maintain stability.

- High-resolution METALLUR scales.

\subsection{Environment}

- $\quad$ Nominal Temperature $20^{\circ} \mathrm{C}\left(68^{\circ} \mathrm{F}\right)$

- Allowable Temperature Range: 18 - $22{ }^{\circ} \mathrm{C}$ (64.4 $\left.71.6^{\circ} \mathrm{F}\right)$

- $\quad$ Extended Temperature Range: $16-26{ }^{\circ} \mathrm{C}(60.8$ - 78.8 ${ }^{\circ} \mathrm{F}$ )

\subsection{Performance Data}

- Hexagon Metrology tests and evaluates Global Silver Edition CMM products using the ASME B89 and ISO 10360 standards.

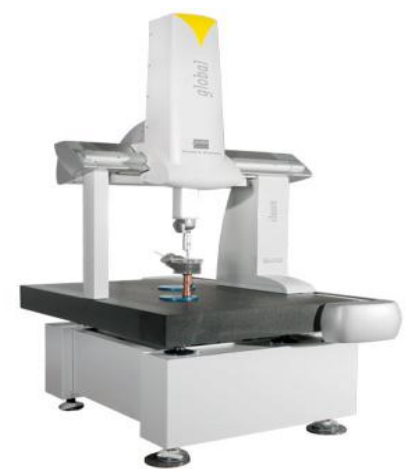

Fig 4 - Microscopic Structure 
Forged Steel EN 36 is equal to HT250, FC250, GG25, G25, FGL250, T260, O125, which is a type of high grade iron. The followings are its application, physical properties and chemical composition.

This iron grade is widely used to produce many castings with high tensile strength and hardness, high degree of tightness or corrosion resistance requirements, such as boiler sprocket wheels, cylinder, gear, bases, flywheels, machinery bed, cylinder block, cylinder liner, piston, gear box, brake wheel, coupling plate, medium pressure valve bodies etc.

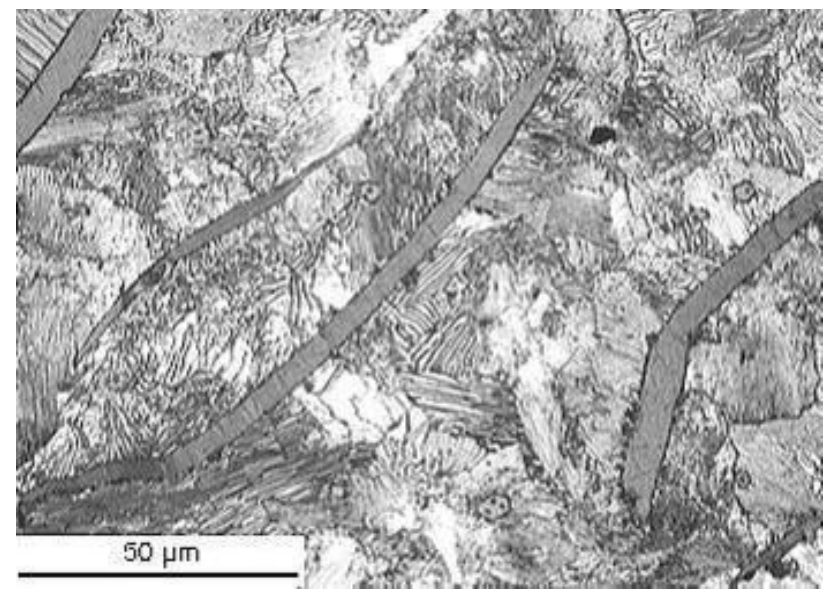

Fig 4 - Brown \& Sharpe Global Classic CMM

Material: Forged Steel EN 36

Table 1: Physical Properties of Forged Steel EN 36

\begin{tabular}{|l|l|l|l|}
\hline \multirow{2}{*}{ Gray } & \multirow{2}{*}{$\begin{array}{l}\text { Single } \\
\text { Cast }\end{array}$} & Specimen & \multicolumn{2}{|l|}{ EN 36 } \\
\cline { 3 - 4 } Iron & Tensile & Wall & Tensile \\
Grade & Strength & Thickness & $\begin{array}{l}\text { Strength } \\
\text { /mm }\end{array}$ \\
& & b $\geq / \mathrm{MPa}$ \\
\hline FG 260 & 250 & $>4.0 \sim 10$ & 270 \\
& & $>10 \sim 20$ & 240 \\
& & $>20 \sim 30$ & 220 \\
& & $>30 \sim 50$ & 200 \\
\hline
\end{tabular}

The metallographic structure should be pearlite. The normal chemical composition varies from $\mathrm{C}=\mathbf{2 . 8 - 3 . 3}, \mathbf{S i}=\mathbf{1 . 2 - 1 . 7}$, $\mathrm{Mn}=0.8-1.2, \mathrm{P} \leq 0.15, \mathrm{~S} \leq 0.12$ to $\mathrm{C}=3.2-3.5, \mathrm{Si}=2.1$ 1.5, Mn = 0.6 - 0.8, P. Max = 0.25, S. Max = 0.15.

\subsection{The Detailed Procedure for CMM Scanning consists of following Steps}

Step 1: Create a New Part Program

To create a new Part Program:

1. Open the PCDMIS program by double clicking on the PCDMIS icon. PCDMIS can also be opened by selecting the Start button, then Program Files | PCDMIS For Windows | Offline. The Open File dialog box will appear.

2. Access the New Part Program dialog box by selecting File | New.

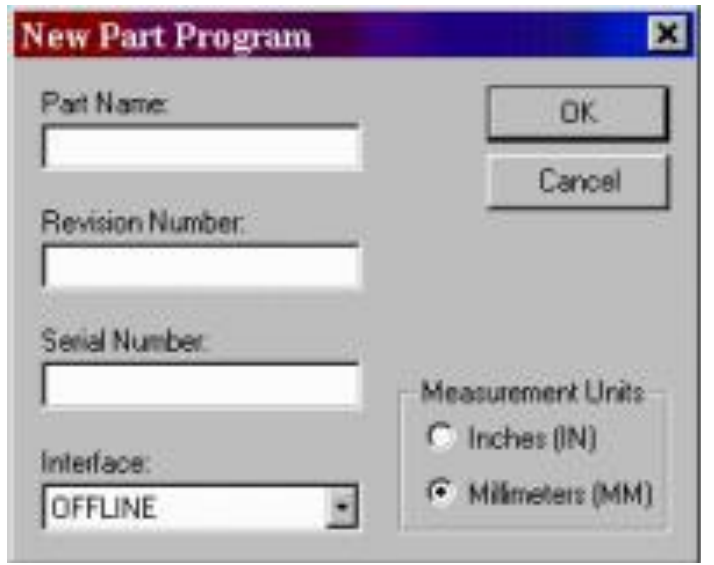

Fig 6 - New Part Program dialog box

3. Click OK. PCDMIS creates the new part program.

\section{Step 2: Define a Probe}

The Probe Utilities dialog box, accessed by selecting Insert | Hardware Definition | Probe, allowing defining a new probe. While first time creating a new part program, PCDMIS automatically brings up this dialog box.

\section{Step 3: Measure a Plane}

Take three hits on the top surface. The hits should be triangular in shape and as spread out as possible. Press the END key after the third hit. PCDMIS will display a feature ID and triangle, indicating the measurement of the plane.

(Note: Verify that PCDMIS is set to Program mode before taking hits. Select the Program mode icon to do this.)

\section{Step 4: Measure a Line}

To measure a line, take two hits on side surface of the part just below the edge, the first hit on the left side of the part and the second hit to the right of the first hit. The direction is very important when measuring features, as PCDMIS uses this information to create the coordinate axis system.

Press the END key after the second hit. PCDMIS will display a feature ID and measured line in the Graphics Display window.

\section{Step 5: Measure a Circle}

Move the probe to the centre of one circle. Lower the probe into the hole and measure the circle, taking four hits in approximately equal distances around the circle. Press the END key after the last hit. PCDMIS will display a feature ID and measured circle in the Graphics Display window.

\section{Step 6: Scale the Image}

After the three features are measured, click the Scale to Fit toolbar icon (or select Operations | Graphics Display Window | Scale to Fit from the menu bar) to display all of the measured features in the Graphics Display window.

The Scale to Fit icon scales the image in the Graphics Display window. 


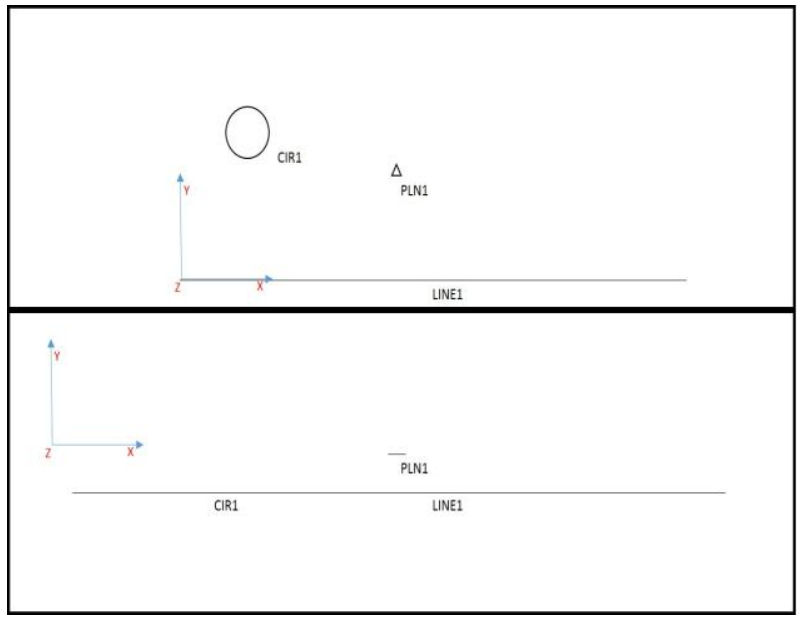

Fig 7 - Display Window Showing Measured Features

\section{Step 7: Set Preferences}

PCDMIS allows customizing PCDMIS to meet specific needs or preferences. There are a variety of options available that can be found within the Edit | Preferences submenu. Only options pertinent to this exercise will be discussed in this section.

\section{Enter DCC Mode}

Select DCC mode. This can be done by either clicking the DCC mode toolbar icon from the Probe Mode toolbar or placing cursor on the line reading "MODE/MANUAL" in the Edit window and pressing the F8 key.

The command in the Edit window will now display: MODE/DCC

\section{Step 8: Measure Additional Features}

Use the probe to measure three additional features.

\section{Step 9: Calculate Dimensions}

Once a feature has been created, the dimensions of that feature can be calculated. Dimensions can be generated at any time while learning a part program, and are tailored to fit individual specifications. PCDMIS will display the result of each dimension operation in the Edit window.

To generate a dimension:

1. Select Insert | Dimension submenu and ensure that the Legacy Dimensions menu item is selected (has a check mark next to it).

2. Access the Location dialog box by selecting Insert | Dimension | True Position.

3. From the list box or the Graphics Display window, select the last three circles that were measured by selecting their feature identifications in the list box.

4. Click the Create button.

PCDMIS will display the locations of the three circles in the Edit window. These values can be changed simply by double clicking on the desired line, highlighting the necessary nominal, and typing in a new value.

\section{Step 10: Mark the Items to Execute}

Marking allows to selectively choosing what elements of part program are executed.

1. Mark all of the features in the part program using the Edit | Markings | Mark All menu option covered in the "Editing a Part Program" chapter. Once marked, the selected features will be displayed using the current highlight colour.

2. PCDMIS asks if it's OK to mark manual alignment features. Click Yes.

\section{Step 11: Set the Report Output}

PCDMIS will also send the final report to a file or printer if selected.

1. Select the File | Printing | Report Print Setup option. The Print Options dialog box appears.

2. Select the Printer check box.

3. Click OK.

There is now enough information to allow PCDMIS to execute the part program that was created.

\section{Step 12: Execute the Finished Program}

There is a variety of options available to execute all or a portion of the part program. See "Executing Part Programs" from the "Using Advanced File Options" section.

Once all of the steps have been followed:

1. Select the File | Execute menu option. PCDMIS will display the Execution Mode Options dialog box and begin the measurement process.

2. Read the instructions in the CMM Command window, and follow the requests to take specified hits.

3. PCDMIS requests to take these hits in the approximate location indicated in the Graphics Display window.

- Take three hits on the surface to create a plane. Press the END key.

- Takes two hits on the edge to create a line. Press the END key.

- Take four hits inside the circle. Press the END key.

4. Click Continue after taking each hit.

When the last hit has been taken on the circle, PCDMIS will display the PCDMIS Message dialog box with your message: "WARNING, Machine is going to DCC mode." As soon as the OK button is clicked, PCDMIS automatically measures the rest of the features.

\section{Step 13: Print the Report}

After the part program is executed, PCDMIS will automatically print the report to the designated output source. This was determined in the Print Options dialog box (File | Printing | Report Print Setup). Since the Printer check box was selected, the report will be sent to the printer. Make sure the printer is connected and turned on to review the part program.

\section{METHODOLOGY ADOPTED}

On the basis of mentioned objectives the following steps are taken:

- Selection of component 
- To scan the component with CMM machine \& obtain point cloud data $\&$ then export this cloud point data of CMM (PCDMIS software) to the modelling software.

- $\quad$ To prepare a CAD model.

- To prepare the inspection program.

\subsection{Selection of Component}

The first step is to find the suitable part for study of complete transmission assembly. Looking at the time period, complexity, functions provided it becomes feasible to take Rotor Driven Shaft as a study component. It is found that the manufacturers of this product do not have the CAD model of this component. So the main problem area of this paper work is concentrated on studying the component \& selecting the best method for developing the CAD model \& error analysis.

\subsection{To Obtain Point Cloud Data}

To obtain point cloud data \& export this cloud point data of CMM (PCDMIS software) to the modelling software:

The term "PCDMIS" is derived from the acronym "DMIS" which stands for: Dimensional Measuring Interface Standard. PCDMIS for Windows incorporates Microsoft's Windows interface to create, as well as execute part programs. The user can easily begin the measurement process by taking advantage of the dropdown menus, dialog boxes, and icons. The versatility of PCDMIS's interface also provides an easy way to customize the software to meet individual specifications.

PCDMIS provides several methods for transmitting CAD geometry, part programs, and measurement data from and/or to $\mathrm{CAD}$ systems. Working with $\mathrm{CAD}$ data is one of PCDMIS's strengths.

CAD geometry can be imported into, and measurement results exported from, PCDMIS via:

- $\quad$ IGES 5.3

- $\quad$ STEP AP203 \& AP214

- VDAFS

- $\operatorname{DES}(2 / 78)$

- XYZIJK format

PCDMIS allows user to import the following for use in generating part programs and as a guide in program execution:

- Two dimensional wire frame

- Two and half dimensional wire frame

- Three dimensional wire frame

- B-spline curves and surfaces CAD models.

This is the actual scan done with the help of Coordinate Measuring Machine with PCDIMS software available at Jadhao Icons Ltd.

\subsection{To Prepare a CAD Model}

Once the point cloud data is generated it is exported to CAD software. In this work CREO software is used. The model developed with CREO is shown below.

CAD modelling with the help of CMM scanning is done by following steps:

1. Scanning with the help of CMM and preparing point cloud data.

2. Importing the point cloud data in the IGS file form to CREO.

3. Making the CAD model with the help of IGS file.

\subsection{Scanning with the help of CMM}

The detailed scanning procedure is already elaborated.

\subsection{Exporting the Point Cloud Data in the IGS File}

\section{Form to CREO}

Once the point cloud data is generated it is then exported to the CREO software.

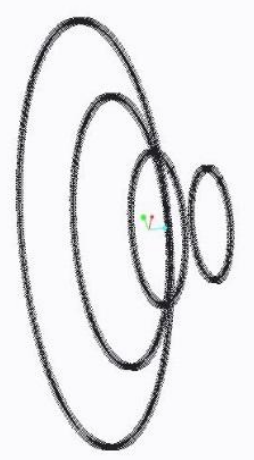

Fig 8 - Scan model of Rotor Driven Shaft

Making the CAD model with the help of IGS file Converting the point cloud data into CAD model consists of two stages.

a. In the first stage, various points obtained by the scanning process are needed to join first. It will give us the profile of the component.

b. In the second stage the profile obtained from the point cloud is converted into CAD model. The CAD model as a result of this is shown below

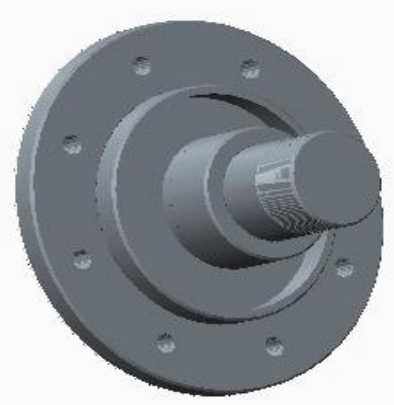

Fig 9 - CAD Model 


\subsection{To Prepare the Inspection Program}

Once the scanning process is completed, the machine is set to run in Direct Computer Control (DCC) mode. In DCC mode the machine is used for inspection activities.

\section{RESULTS \& DISCUSSION}

Table 2 - Comparison between Manual/Conventional Measurement \& CMM - Manual Measurement

\begin{tabular}{|l|l|l|l|l|}
\hline $\begin{array}{l}\text { Sr. } \\
\text { No. }\end{array}$ & Part & $\begin{array}{l}\text { Manual } \\
\text { Measure- } \\
\text { ment } \\
(\mathbf{m m})\end{array}$ & $\begin{array}{l}\text { CMM } \\
\text { Manual } \\
\text { Measure- } \\
\text { Ment } \\
(\mathbf{m m})\end{array}$ & Deviation \\
\hline 1. & Circle A & 154 & 154.124 & 0.124 \\
\hline 2. & Circle B & 98 & 98.131 & 0.131 \\
\hline 3. & Circle C & 55 & 55.057 & 0.057 \\
\hline 4. & Circle D & 40 & 40.01 & 0.1 \\
\hline 5. & Height 1 & 10 & 10.106 & 0.106 \\
\hline 6. & Height 2 & 26 & 26.103 & 0.103 \\
\hline 7. & Height 3 & 39 & 39.57 & 0.57 \\
\hline 8. & $\begin{array}{l}\text { Concentricity } \\
\text { of Circle C } \\
\text { with Circle D }\end{array}$ & $0.02(\mathrm{D})$ & 0.007 & 0.013 \\
\hline 9. & PCD of holes & 124 & 124.097 & 0.097 \\
\hline
\end{tabular}

Error criteria set by the industry for rejection of component is $0.1 \mathrm{~mm}$. Parts above $0.1 \mathrm{~mm}$ error are rejected. It was found that the task of assembly is affected with any error above 0.1 $\mathrm{mm}$. Hence the industry needs better inspection activity and effective error analysis method. So from the study of above table, it is clear that the CMM scanning method is better method for error analysis as compared to manual scanning since the points considered for scanning is more. Whereas the manual method consists of scanning based on considering minimum points.

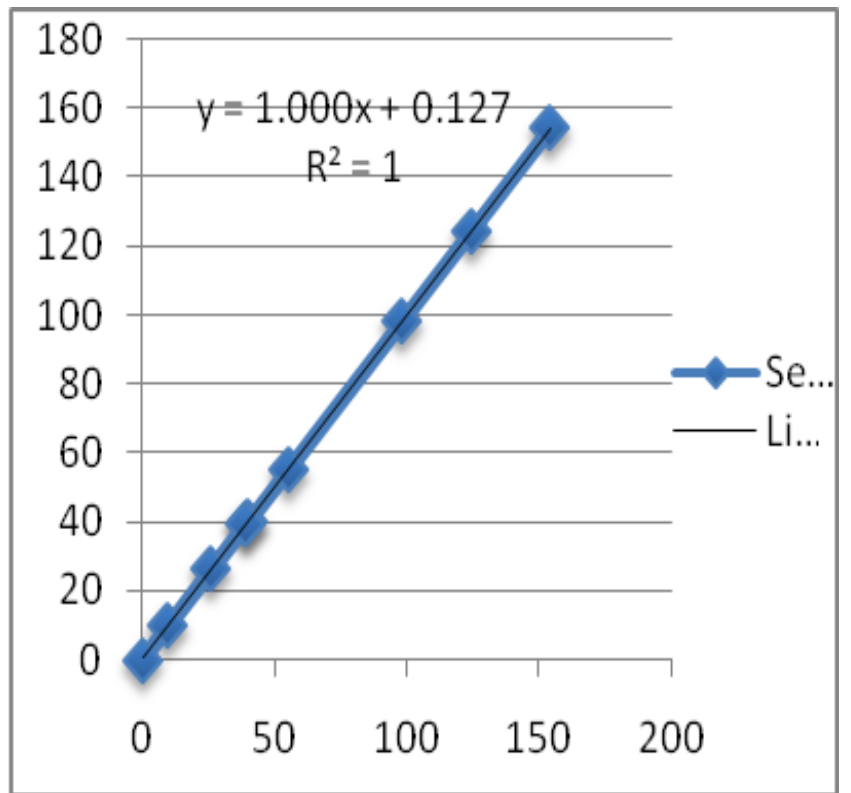

Graph 1 - Deviation between Manual Measurement (X-axis) \& CMM Manual Measurement (Y-axis)
So, from the graph it can be said that for the purpose of error analysis, CMM scanning method is a good alternative as compared to conventional manual measurement method. This method is not only cheap but it also proves to be a time saving method.

\section{CONCLUSION}

Out of the complete assembly, Rotor Driven Shaft is selected for study purpose because of the time limitations, functions $\&$ complexity. Once the optimal method of error analysis is chosen, it may be employed for other parts.

In this paper work the Coordinate Measuring Machine (CMM) is studied \& scanning of the Rotor Driven Shaft is done with the help of CMM. By the virtue of this scanning, point cloud data is obtained. This point cloud data is exported from the CMM (PCDMIS software) to the modelling software CREO.

With the aid of modelling software CREO point cloud data is converted into CAD model.

The Rotor Driven Shaft is then analysed using conventional method as well as using CMM. It is found that CMM scanning measurement method is the best method for error analysis.

\section{REFERENCES}

[1] G. C. Gannod, B. H. C. Cheng, A Formal Approach for Reverse Engineering: A Case Study, Proceedings of the 6th Working Conference on Reverse Engineering, Oct 1999, pp. 100-111.

[2] C. Xue Feng and S. Xiao, Computer-Aided Reverse Engineering with CMM for Digitization and LOM for Duplication, Proceedings of the fourth International Conference on Frontiers of Design and Manufacturing, 2000, pp. 256-262.

[3] V.H. Chan, C. Bradley, G.W. Vickers, A multi-sensor approach to automating co-ordinate measuring machine-based reverse engineering, Computers in Industry 44 (2001) pp.105-115.

[4] L. Li, N. Schemenauer, X. Peng, Y. Zeng, P. Gu, A Reverse Engineering system for rapid manufacturing of complex objects, Robotics and Computer Integrated Manufacturing 18 (2002), pp. 53-67.

[5] S.Ali, textbook on Reverse Engineering of Mechanical Parts.

[6] M. Sokovic, J. Kopac, RE (reverse engineering) as necessary phase by rapid product development, Journal of Materials Processing Technology 175 (2006), pp.398-403.

[7] M. M. Hussain, S. Rao, K. E. Prasad, Reverse Engineering: Point Cloud Generation with CMM for Part Modeling and Error Analysis, ARPN Journal of Engineering and Applied Sciences, VOL. 3, NO. 4, PP.37-40. 
[8] T. S. Babu and R. D. Thumbanga, Reverse

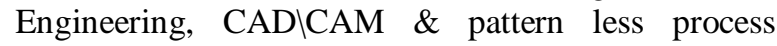
applications in casting-A case study, International Journal Of Mechanics, Issue 1, Volume 5, 2011, pp.40-47.

[9] N. Singh, Reverse Engineering- A General Review, International Journal of Advanced Engineering Research and Studies, Vol. II/ Issue I/Oct.-Dec., 2012. Pp.24-28. 